\title{
ONLINE TABLE RESERVATION WITH PRE-ORDERING
}

\author{
Dr.K.Subrahmanyam ${ }^{\text {a }}$, Dattatreya Viswanadham ${ }^{\text {b }}$, Are Sujith ${ }^{\mathrm{c}}$, Rahul Devavarapu ${ }^{\mathrm{d}}$ and Koneru SusmanthVenkat ${ }^{\mathrm{e}}$ \\ EDepartment of Computer Science and Engineering, Koneru Lakshmaiah Educational Foundation, 522502, Andhra Pradesh, \\ India
}

Article History: Received: 11 January 2021; Accepted: 27 February 2021; Published online: 5 April 2021

\begin{abstract}
Online Table Reservation System is aweb-based solution for a Restaurant's Pre-Ordering module; automation and digitalization of table reservation process along with pre-ordering of food and parking spot allocation. This system would allow restaurants to increase the scope of business and save a lot of time with table reservations as previous bookings are open. The system also makes it possible to quickly and easily control an online menu that customers can search and use with only a few clicks to place orders. Recommendations would be based on user activation and specifications. A new user would be recommended of the restaurants available best sellers while a regular would be recommended based on their previous food selections. Their starter and other food selections would also raise recommendations. The table will be reserved along with a parking space on the appropriate time-slot so that users do not face inconvenience. Using this system as a building block, we can develop a smartphone-compactable software application.
\end{abstract}

Keywords: Pre-Ordering System, Table -Reservation, Parking lot allocation, Process Automation, Food recommendation, Restaurant automation.

\section{Introduction}

Table reservation is one of the main functionalities of a restaurant, serving not only customers with their culinary talent but also with their service. But one of the problems they face would be parking allocation for their customers. Due to other parameters which wouldn't be resolved without human intervention, the solution we came up with was to allocate a parking slot a few minutes before the decided time to the user so that they would not be prepared for their arrival but also makes them feel content. The basic feature of our system is the services it offers, ranging from providing contact information to booking a table with a preordered menu at a chosen time slot. As the regular reservation system functions like this is different from the normal one. We pick a table, we wait for a free parking spot, we get in the restaurant, we order food, we wait for it. As we can see, when opposed to the functionality of our reservation system, this is inefficient as there is a lot of waste of time going on. Not only have we established a booking slot for a working table, but we also assign a free parking slot a few minutes before the booking period. This project also involves a menu management system that allows hotel management to carry out actions on the menu displayed on the websites, thereby helping to maintain a live menu that is updated. Using past user requests or commonly requested objects, the suggested framework for improved user experience can be implemented. Based on the ordered menu details we can develop a menu recommendation system which as specified in the Abstract studies the common trends and combinations in food ordering and would recommend food combinations based on this data analysis. This whole system is implemented as a user interface by developing a web application that not only features a menu display and updating module such as a standard restaurant website but also allows the user to pre-request a time slot booking for a table and parking slot and also a pre-ordered menu that must be freshly served at the time of arrival. To build a strong customerrestaurantpartnership we can also implementPre-orders for dine-in. Technology that brings online sales and makes guests happy. Restaurants already speak to guests via the web-Site. It allows reservation service and they can even cook and serve with dine-in preorders. Selling is done in advance. Guests have neat menus presented to them in the system and it is easy for them to place order requests. Increase table turn-over: restaurants get busy and lose many customers with a lot of people waiting for their meals. Factors to blame for service delays would be slow menu ordering, preparation of food and paper checks. Dine-in pre-orders help to prevent inconvenience and improve table turnover by skipping booking, food preparation and checkout delays. To address the needs of busy diners, ordering ahead is created. They're able to just dine in and leave when these guys come to a restaurant, so there's no over-stay. Keep busy diners happy: It can take too much time for busy individuals to have nourishing meals at restaurants. Some waiting is always bothersome.

Dine-in preorders address the issue of waiting for a seat, eating and testing and taking busy people back to restaurants. Restaurants may have better dining experiences by understanding the orders of guests beforehand. Here's how to look ahead from the guest's point of view. Your table is ready, your meal is served in a snap, you just eat, say thank you, and you leave.

\section{Flow Chart}




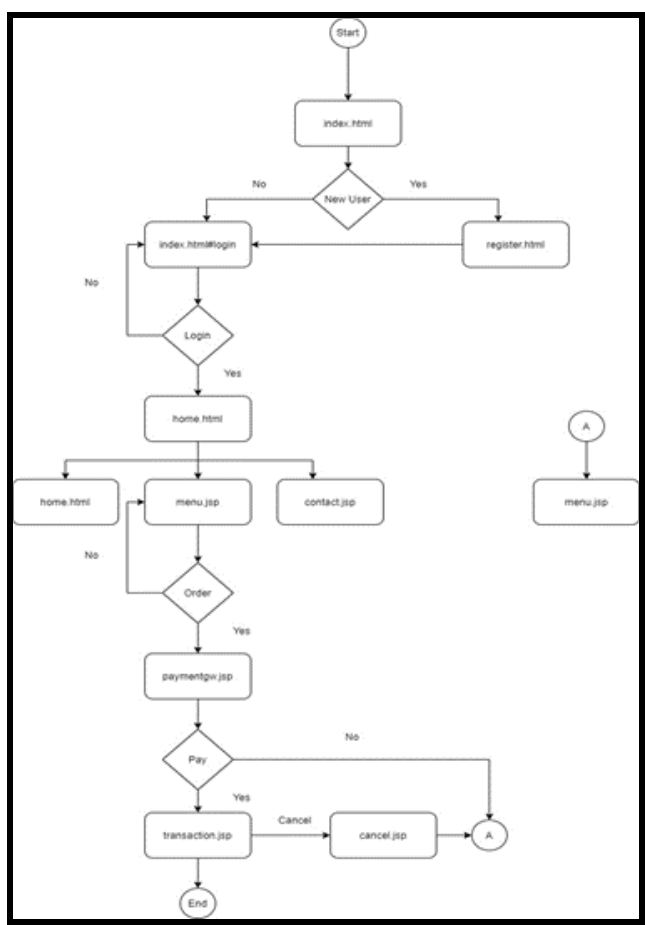

Fig 2.1.: The above flowchart depicts the user experience a user would emulate when they interact with the system.

\section{User Perspective \& Implementation Methodology}

The user's first interaction with the system is with anHTML page named 'Index.html', which redirects to the login page. If the user was already a registered one, they can proceed with login with the help of their credentials. Else, users can register by going to the registration page by clicking on the register button. The navigation bar on this page contains a live-updated food menu. User can select the required items and add them to the cart. Once satisfied with his selection, they can proceed to the payment module. After payment, the table reservation page is accessed. This page shows the billing details (containing food items, their respective cost along total cost) along with the reserved table and parking slot details.

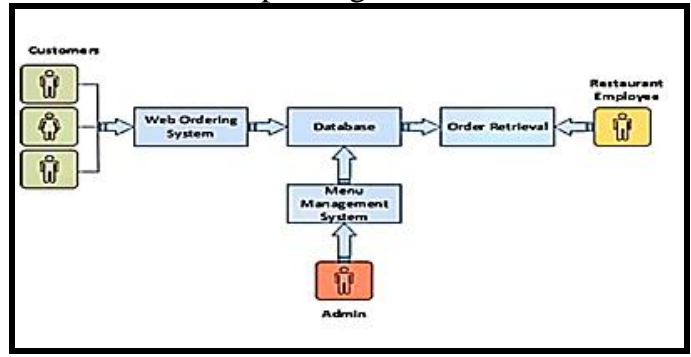

Fig 3.1.: The above flowchart depicts the web ordering system's overview functionalities.

\section{Admin's Perspective \& Implementation Methodology}

The other module of this project is the Admin module. This module starts with a user login with admin credentials. This sends them to the admin form of the home.html page where they can access the menu in the navigation bar. They can perform updating of price for an item, adding new items to the menu or removing the existing items that aren't available at that time. We can automate this process by connecting this web-page based database to the kitchen monitoring module (if exists), which can make this project a whole lot accurate and convenient. Once a customer leaves the table before his completion time, the admin can change the table status to free and make it available for other users.

\section{ImplementedTechnology \\ Bootstrap Framework}

Bootstrap is a free and open-source CSS platform for mobile-first front-end web creation that is sensitive. As such, whether the developers in control find those choices to their taste is the primary factor. In the form of jQuery plugins, Bootstrap also comes with several JavaScript components. 


\section{Experimental Procedure}

Several steps in the process were added. So, we separate the entire process into four modules, one for each student.

Module-1: Login Module \& Register Module

Module-2: Menu Module

Module-3: Table Reservation and Billing Module

Module-4: Admin ModuleQueries, aggregations functions such as Map-Reduce uses JavaScript and will be sent to the execution to the database directly.

Module-1: Login Module \&Register Module This is the first thing the user gets interacted with. Here, there are again two modules login and register.Here, if the user has an account,then he can login by giving an email and password in the respective column.If the login is successful,then the user will be directed to the home page.

Otherwise, if the user tries to login without registering, the login fails and a message is shown in the "Failed" alert window. If the user is new to the web application, then he can click on the option to register and register with information such as email, password, phone number, and current password. If the validation is met by the credentials, the user will be registered and the user will be directed to the login page.

Here, the user should retype the same email id and password that he gave while registering and then if satisfied, he will be directed to the home page.

Module-2: Menu Module

After the user got directed to the home page, there he can get visible with a menu option. Now, the user can click the menu and then he can get visible with various options of the food items.

There are 4 categories in this menu:

1. ALL ITEMS

2.VEGETARIAN

3.NON-VEGETARIAN

\section{DESERTS}

Now with the filter option in use, you can select based on the user's preference. If the user chooses the ALL option, then all the food items without any filtrations will be displayed. If the user clicks the options of vegetarian then the vegetarian dishes will be displayed, else if he chooses non-vegetarian user gets all nonvegetarian dishes displayed. If the user clicks on the Deserts then, all the deserts will be displayed.

Now vegetarian and Non-vegetarian are again further divided into two types:

1.STARTERS

2.MAIN COURSE

Now in the main course, it is again sub-divided into 3 types:

2.1. SINGLE PACK

2.2. FAMILY PACK

2.3. JUMBO PACK

Now, in deserts it is again sub-divided into 3 types:

1. PASTRY

2. SWEETS

3. ICE-CREAMS

Module-3:Table Reservation and Billing Module

Here the items that the user selects will be attached to the cart. A pop-up showing the cost of items and an option to search the list will be given to the user. If the user clicks on the payment option, a reservation card will be created for the user. Email id, table no and parking slot no, list of selected items, cost of items like reservation number and VAT are the information that will be shown on the reservation card after billing. The number of the parking slot is equivalent to the number of the table and will not be changed until given until the time slot has been filled. If the user wishes to cancel the reservation, he should click on the option to cancel the reservation and the balance will be refunded based on the time slots

\section{Module-4: Admin Module}

This is a module for maintenance and back-end that is not accessed by the user but has a great effect on the experience of the user. Entry to this module is only permitted by approved staff and this starts with admin accessing 'Index.html', which redirects to the login page, which needs admin credentials. Such credentials are sent to 'checklogin.jsp'. They are redirected to 'home.html' if user authentication is successful. From here in their session, they can access 'Menu.html,' which contains the menu from which the user can choose. The administrator will adjust the things that the menu displays. 'additem.jsp' can help the administrator add a new item to the hotel menu, 'removeitem.jsp' can do the reverse of additem.jsp; i.e., delete an item that is not included in the list of things in the menu. Depending on different parameters related to that and demand, 'changeprice.jsp' helps adjust the pre-defined price of an item in the list.

Module-5:Main Module 
Online Reservation System with Pre-Ordering project does follow a hierarchical flow while traversing along with the project. When the web application launched in a web browser index.html does load as a start-up page. This page does include information about the portal along with the Login module. After logging in the user is redirected to the home.html from where he can access various pages to utilize the functionalities developed by developers.

The Whole User Interface in this web application is designed using a UI tool called Bootstrap 4. It provides container and grids to design a UI more aesthetically pleasing. The key feature that the user can use is to filter the menu based on the filter-items, for which we used another bootstrap feature called "filter-button, data-toggle and data-target" where a user can filter categories such as veg, non-veg and deserts based on them.The menu cards on the menu page are loaded from the Oracle Database Menu Table on the host machine. JDBC accomplishes the connection between java code and database in which we follow several steps to attach and run a query, which is called the JDBC life cycle. We will then extract the data from the Database Menu Table. The retrieved data can be displayed in the web application by using expression tags in JSP to include it in the HTML.By clicking the add and delete keys, the user may then add or remove the items from the list. The "btn" bootstrap class is used to design the delete button. The values are added/removed from the cart by pressing these buttons using a JS feature that is evoked by the on-click event listener. This feature adds and removes products from the cart using the getElementById function.Adding the items into the cart, the user can pay the amount and book his reservation by clicking the pay button at bottom of the page. By clicking this button it redirected the user to the payment gateway where he can pay the amount to book the items.After payment is successful he will be redirected to the reservation page where he can find his reservation card which is proof of his reservation. The user has the flexibility to cancel the reservation and again he can book his table with a new order.

\section{Literature Survey:}

\section{Smart parking system with pre \& post reservation,billing and traffic app}

Different smart apps such as smart home are heading towards smart city growth. A significant component of the so-called smart city is the smart parking system of these apps. The intelligent parking system allows the parking spot to be reservedin advance, which helps to minimize the time spent looking for a parking spot, reduce traffic congestion, reduce noise, reduce driver annoyance, etc. A smart internet-based parking system in this paper that not only allows drivers to book a specific parking space, but also helps in automated cashless billing, Hacking intimation, post-trip booking, is proposed. In terms of smart cities, the proposed framework offers all the features required to enhance the quality of life of a person.

\section{Design and Implement An Online Restaurant Reservation System:}

The ultimate objective of this project is to develop and implement an online restaurant booking system that would enable diners to order food and reserve restaurant tables to maximize food ordering and table booking. For the analysis, cross-sectional research and quantitative approach were taken. To choose a sample size of 20 team members, a non-random quota sampling technique was used. To gather data from the workers, questionnaires were introduced. Knowledge has been analyzed descriptively. The study's results showed that Best Point Savings and Loans Limited's Consumer Relationship Marketing Approach generates and retains profitable clients. Effective implementation of Relationship Marketing by winning consumer trust and loyalty, implementing customer-centred processes, producing customer data and knowledge capabilities, and selecting and implementing technology solutions using employee empowerment.

The different ways in which Customer Experience Marketing techniques are applied by Best Point Savings and Loans Limited include quality of service, price perception, customer profitability (add-on selling), brand image, customer equity, relationship customization, service augmentation, and internal marketing. Including the advantages of Customer Experience Marketing as a strategic strategy at Best Point Savings; developing and strengthening customer confidence. Customer relationship marketing as a strategic marketing tool can be related to the 4Ps. CRM typically enables companies to establish long-term partnerships with existing and new clients while helping to restructure corporate performance.

\section{Wireless Food Ordering System Based on Web Services}

Rapid advances in information technology, especially in technology for wireless communication and web services, are changing the way people access and work with information. The ease and powerful features provided by mobile devices such as PDAs have inspired many individuals to explore the advantages of using them. As vendors pitch the traditional concepts of one-to-one computing, instant connectivity and access to information anytime, anywhere, wireless and portable devices abound. While web services provide a serviceoriented computing technology. Web services allow programs written on different platforms in different languages to communicate in a standard way with each other. Consistent business models can be implemented on a broad array of devices by integrating these technologies: Not only on mobile devices that run over mobile networks but also on servers and Internet-connected PCs. Instruction flows primarily to the cashier, from customers to waiters, then to the kitchen and/or bar staff. This teamwork is a challenge in a medium-to-large and busy restaurant and involves an effective ordering system. Errors in ordering procedures result in an incorrect or 
out of sequence meal repair or no consumables, resulting in additional expense to the company. This paper presents an integration of wireless communication technologies and web services technologies to realize a wireless food ordering system. The framework is based on a stable architecture of web services and adopts such security strategies to ensure the security of mobile communication.

\section{Online Food Pre-Ordering System (Case Study)}

Pre-ordering is the option of ordering food for a specific day and time on the website or mobile application. The time when the order is to be prepared can be specified by clients who order food online for take-out or delivery. When the client wants to order food in advance and dine-in, the situation is identical. They can pre-order food to be prepared for a certain period using an online food ordering system. Then, they do not have to wait for the order to be prepared at the table. On your restaurant website or mobile app, all you need is the Up-Menu framework to sell pre-order meals. It's super simple-just tell your clients about this choice for ordering. For clients, you can develop unique promotions, introduce them to new features, and publish articles on social media about them. When your guests ask the waiters why they have been waiting for food for so long, notify them that they can order online earlier next-time. You would be able to increase the number of orders and your earnings with these easy acts. Start a trial free of charge and see for yourself. No matter where or when the customers will be able to order more quickly and conveniently. The Up-Menu system with the pre-order option offers ordering convenience like this all they have to do is pick the day and time when they want to get food.

They also refertheirfriendsandfamilytoyourrestaurant.Thisallleadstoincreased sales 26\%ofcustomersstatethattheofferingofpre-orderingoptions

for you. restauranthasasignificanteffecton where they want to dine, and $45 \%$ of customers consider it to be one of the mos t important considerations when selecting a restaurant.In line, they won't have to wait! They skip the line both when ordering dine-in, and with the option of delivery and takeout. They save time, don't get annoyed, and your service is more rewarding. We would be able to arrange their working time more easily and be more efficient.

They can understand when they should expect a greater number of clients at the restaurant and when they will have more orders to complete or carry out for delivery. As a result, more consumers, who are also not upset at having to wait for their order at the table or waiting to be seated, will have services. At your restaurant, they are happier with the level of service and they visit more often. More efficient workers manage more happy customers who spend more money at your restaurant and invite their friends together to enjoy the meals you cook. Thanks to a food delivery app with the option of pre-ordering, anything is possible. The possibility of preordering can offer the best online food ordering system.

For a particular date and time, they may also order the delivery of food. This will help you coordinate restaurant assignments and fulfil the needs of customers. As a consequence, you'll boost profits and bypass your competition. In the Up Menu system, find out more about table reservations that will avoid cancelled reservations from happening at your restaurant when combined with pre-ordering!

\section{Problems with Existing work}

In nearly all of the existing restaurant booking systems deals with booking table and ends with it. This means a user has to deal with parking issues themselves and also wait for food which costs them a lot of time. Not to mention, this whole process is traditional and can be simplified with the interference of modern technology.

\section{Proposed Work}

Here in our web application, the customer can reserve a table along with ordering the food which is also called pre-ordering. Here, the customer will not face the problem i.e. the waiting time will be reduced and the food will be served immediately by the time the customer reaches the hotel.

\section{Advantages with Proposed Work}

The waiting time between the occupancy of the table and food serving is reduced here. It makes all the data transactions online and stored in the database. There will be work management and no sort of disturbances occur during the business.

\section{Conclusion}

As we mentioned before, most restaurant websites offer new services every day but in terms of time management, most of them are unsuccessful. Although there are a few websites that have a framework for table reservations, most of them stop there. Only after they enter the location do users have to order food. Not to mention, the scarcity of parking slots is also a problem.By implementing a food ordering system along with the option of reserving a table with relative parking space, our project provides a fundamental working solution for all the stated problems. This not only addresses the issue statement we were studying on but also offers a smooth user interface. We also have an admin module to do the required background work which includes live updating of the hotel menu and control of the table and parking lot based on the user's requests. This makes it a lot simpler and comfortable for the user experience. By implementing a mobile application for personalized and hand-held experience, further advancement in this field can be introduced. With the support of third-party food delivery applications such as Swiggy, Zomato and others, we can also bring personalized food delivery to users. Modern web hosting services and groundbreaking technical reforms ranging from Cloud, IoT to Cyber Security can also 
be used to make users more social. We hope this project can help others working on developing applications in a similar field.

\section{REFERENCES}

1. N. Rianthong, A. Dumrongsiri and Y. Kohda, "Maximizing service value: A case study of online hotel reservation", 2014 IEEE International Conference on Industrial Engineering and Engineering Management, pp. 803-807, 2014.

2. Chavan, V., Jadhav, P., Korade, S., \&Teli, P. (2015). Implementing Customizable Online Food Ordering System Using Web-Based Application. [3] S. Patil, S. Gudasalamani, and N. C. Iyer, "A survey on Iris recognition system," 2016 International Conference on Electrical, Electronics, and Optimization Techniques (ICEEOT), Chennai, 2016, pp. 2207-2211, DOI: 11.1119/ICEEOT.2016.7755084.

3. T. Tan, C. Chang and Y. Chen, "Developing an Intelligent e-Restaurant With a Menu Recommender for Customer-Centric Service," in IEEE Transactions on Systems, Man, and Cybernetics, Part C (Applications and Reviews), vol. 42, no. 5, pp. 775-787, Sept. 2012, DOI: 11.1119/TSMCC.2011.2168560.

4. Ranjan, Vivek \&Masiwal, Nikesh \& Verma, Nikita \&Bharadi, Vinayak. (2013). e-Restaurant: Online Restaurant Management System for Android. International Journal of Advanced Computer Science and Applications. 3. 11.14569/SpecialIssue.2013.030118.

5. Soon Nyean Cheong, Wei Wing Chiew and Wen Jiun Yap, "Design and development of Multi-touchable E-restaurant Management System," 2011 International Conference on Science and Social Research (CSSR 2011), Kuala Lumpur, Malaysia, 2011, pp. 680-685, DOI: 11.1119/CSSR.2011.5773867.

6. H. Saeed, A. Shouman, M. Elfar, M. Shabka, S. Majumdar and C. Horng-Lung, "Near-field communication sensors and cloud-based smart restaurant management system," 2016 IEEE 3rd World Forum on Internet of Things (WF-IoT), Reston, VA, 2016, pp. 686-691, DOI: 11.1119/WFIoT.2016.7845440.

7. V. Liyanage, A. Ekanayake, H. Premasiri, P. Munasinghe and S. Thelijjagoda, "Foody - Smart Restaurant Management and Ordering System," 2018 IEEE Region 11 Humanitarian Technology Conference (R11-HTC), Malambe, Sri Lanka, 2018, pp. 1-6, DOI: 11.1119/R11-HTC.2018.8629835.

8. Bharadi, Vinayak \& Ranjan, Vivek \&Masiwal, Nikesh \& Varma, Nikita. (2013). Intelligent e-Restaurant using Android OS. 11.5120/icwac1311.11] Lemieux, Victoria. (2017). Blockchain and Distributed Ledgers as Trusted Recordkeeping Systems: An Archival Theoretic Evaluation Framework.

9. Williams, W., \& Simmonds, D. (2011). A Case Study in the Design of a Restaurant Management System. FECS.

10.Dr Vinayak Ashok Bharadi, Vivek Ranjan, Nikesh Masiwal and Nikita Verma, "e-Restaurant: Online Restaurant Management System for Android" International Journal of Advanced Computer Science and Applications(IJACSA), Special Issue on Selected Papers from International Conference \& Workshop On Advance Computing 2013, 2013. http://dx.doi.org/11.14569/SpecialIssue.2013.030118 